\title{
Organophosphate Poisoning among Patients attending Kericho County Hospital, Kenya.
}

\author{
R. K. A. Sang ${ }^{1}$, J. Kimani ${ }^{2}$ \\ ${ }^{1}$ Egerton University (Faculty of Health Sciences) \\ ${ }^{1}$ Egerton University (Community Health Department)
}

\begin{abstract}
Organophosphate compounds are a diverse group of chemicals used in both domestic and industrial settings. Their application is still the most effective and accepted means for the protection of plants from pests, and has contributed significantly to enhanced agricultural productivity and crop yields. Some have also been used in the medical treatment of various disease conditions. The common use of insecticides in public health and agricultural schedules has caused severe environmental pollution and potential health hazards including severe acute and chronic cases of human and animal poisonings. This cross-sectional study sought to determine the prevalence of organophosphate poisoning among the community living around Kericho County Hospital. Purposely selected patients aged 15-40 years attending Kericho County Hospital were interviewed and data collected was analysed using Microsoft excel and SPSS.Results showed that organophosphate poisoning accounted for $5 \%$ of patients attending the County Hospital. Analysis of data from patients interviewed revealed that their poisoning was intentional and none was due to occupational exposure. Males accounted for the larger percentage (74\%) against a female percentage of $26 \% .94 \%$ of the patients admitted had relationship being a reason for taking poison while 46\% had an intention to die and were among those admitted during the night.
\end{abstract}

\author{
Abbreviations and Acronyms \\ WHO: World Health Organisation \\ MOH: Ministry of health \\ $\mathbf{K m}^{2}$ : Square kilometres \\ OP: Organophosphates \\ DFP: Diisopropylphosphorofluoridate \\ TEPP: Tetraethyl pyrophosphate \\ OMPA:Octomethylpyrophosphotetramide \\ DDT: Dichlorodiphenyltrichloroethane \\ UNEP: United Nations Environmental Programme \\ DNA: Deoxyribonucleic Acid \\ RNA: Ribonucleic Acid \\ Ach:Acetylcholine \\ AchE: Acetyl cholinesterase \\ RBC: Red Blood Cell \\ Definition of Terms \\ Hypopnoea: Breathing that is shallower or slower, than normal. \\ Apnoea: Absence of breathing.
}

Hepatitis: Inflammation of the liver, due usually to viral infection but sometimes to toxicagents.

Myocardium: The middle layer of the heart, consisting of heart muscle.

Neurotransmitter: Any specific chemical agent (including acetylcholine, five amines, fouramino acids, two purines, and more than 28 peptides) released by apresynaptic cell, on excitation, that crosses the synapse to stimulate orinhibit the postsynaptic cell. More than one may be released at any givensynapse.

Acetylcholine: A neurotransmitter.

Acetyl cholinesterase: An enzyme that hydrolyses acetylcholine.

Hydrolyse: Removal of $\mathrm{H}$ and $\mathrm{OH}$ as water; the process leads to formation of new double bondswithin the affected molecule.

Hypoglycaemia: Symptoms resulting from low blood glucose (normal glucose range 60-100mg/dL [3.3-5.6

\footnotetext{
${ }^{1}$ Egerton University ( Faculty of Health Sciences)

${ }^{2}$ Egerton University ( Community Health Department) 
$\mathrm{mmol} / \mathrm{L}])$.

Glycosuria: Urinary excretion of carbohydrates.

Hypokalaemia: The presence of an abnormally low concentration of potassium ions in thecirculating blood. Leucocytosis: An abnormally large number of leukocytes, as observed in acute infections,inflammation, haemorrhage, and other conditions.

VX:An extremely toxic persistent chemical warfare agent $\mathrm{C}_{11} \mathrm{H}_{26} \mathrm{NO}_{2} \mathrm{PS}$ that is usedespecially as a nerve gas and that in large doses typically causes convulsions, loss ofconsciousness, paralysis, and failure of the respiratory system leading to death.

\section{Introduction}

Organophosphorus (OP) compounds have been widely used for a few decades in agriculture for crop protection and pest control. Thousands of these compounds have been screened and over one hundred of them have been marketed for these purposes [Nature and Science, 2009]. OPs constitute a heterogeneous category of chemicals specifically designed for the control of pests, weeds or plant diseases. Their application is still the most effective and accepted means for the protection of plants from pests, and has contributed significantly to enhanced agricultural productivity and crop yields [Claudia Bolognesi. Mutation Research, 2003].Some have also been used in the medical treatment of myasthenia gravis, e.g. Diisopropylphosphorofluoridate (DFP), tetraethyl pyrophosphate (TEPP) and Octomethylpyrophosphotetramide (OMPA). Some OP esters are still used to treat glaucoma (Ecothiopate). In addition to these beneficial agricultural, veterinary, and medical uses, some highly potent OP anticholinesterase compounds, including tabun, sarin, soman, and VX have been used as "nerve gases" in chemical warfare. They have also been used as plasticizers and stabilizers in lubricating and hydraulic oils, flame retardants, and gasoline additives [Clinical Neurology and Neurosurgery, 1992].

A total of about 890 active ingredients are registered as pesticides in USA and currentlymarketed in some 20,700 pesticide products. U.S pesticide expenditures totalled more than $\$ 11$ billion in 2000 and 2001 [US EPA Pesticide Industry Sales and Usage: 2000 and 2001].

Many of these compounds, because of their environmental persistence, will linger in our environment for many years to come. All people are inevitably exposed to pesticides, through environmental contamination or occupational use.

The general population is exposed to the residues of pesticides, including physical and biological degradation products in air, water and food. Occupational exposure occurring at all stages of pesticide formulation, manufacture and application involves exposure to complex mixtures of different types of chemicals, active ingredients and by-products present in technical formulations such as impurities, solvents and other compounds produced during the storage procedure.

Moreover, although inert ingredients have no pesticide activity, they may be biologically active and sometimes the most toxic component of a pesticide formulation. Pesticides act selectively against certain organisms without adversely affecting others. Absolute selectivity, however, is difficult to achieve and most pesticides are a toxic risk also to humans. The organophosphate compounds are most commonly associated with serious human toxicity, accounting for more than $80 \%$ of pesticide-related hospitalizations [Clinical management of poisoning and overdose, 1983].

The common use of insecticides in public health and agricultural schedules has caused severe environmental pollution and potential health hazards including severe acute and chronic cases of human and animal poisonings [AA Moghadamnia, M Abdollahi. East Mediterr Health J, 2002]. Currently no data is available regarding extent of OP poisoning in Kenya.

\subsection{Statement of the Problem}

The organophosphate compounds are most commonly associated with serious human toxicity, accounting for more than $80 \%$ of pesticide-related hospitalizations [Clinical management of poisoning and overdose, 1983]. In contrast to the past, when chlorinated hydrocarbon compounds such as DDT were commonly used, organophosphate insecticides have become increasingly popular for both agricultural and home use because their unstable chemical structure leads to rapid hydrolysis and little long-term accumulation in the environment. This widespread use, however, has resulted in increased numbers of human poisonings. Throughthe 1970s, the Environmental Protection Agency estimated that 3,000 hospitalizations per yearwere required for insecticide poisoning in the United States, with a fatality rate of 50\% in thepaediatric age group and $10 \%$ in adults [National study of hospital admitted pesticide poisoningsfor 1974 to 1976]. In 1983 data from the American Association of Poison Control Centres indicated that the national incidence of insecticide exposures was 77,000, of which 33,000 involved organophosphates [J Veltri, T Litovitz: 1983]. The continued use of such 
Organophosphate Poisoning Among Patients Attending Kericho County Hospital, Kenya.

chemicals will likely increase these statistics in the future. No such information was available nationally in Kenya and locally at Kericho County.

\subsection{Justification}

Globally, $80 \%$ of pesticide related poisoning is attributable to organophosphate compounds [Clinical management of poisoning and overdose, 1983]. The epidemiology of poisoning in Kenya, as in other African countries, is not well established. However, for Kenya which has few established poison information centres, hospital toxicology vigilance is important in providing epidemiological information that can be used in the design of focused interventions. There exists no data on organophosphate poisoning specific to Kericho County and thus a knowledge gap exists leading to need to establish the prevalence of organophosphate and also factors that predispose individuals to organophosphate poisoning. Once these factors are identified, measures can be taken in order to reduce the burden of organophosphate poisoning in the county. This will not only reduce morbidity and mortality from the toxic effects but also reduction on the social and economic burden that comes with it. This research aimed at establishing such factors which in turn will lead to putting in place appropriate measures to mitigate the same.

\subsection{Objectives}

\subsubsection{Broad Objective}

To determine the prevalence of organophosphate poisoning among patients aged between $15-40$ attending Kericho County Hospital in the months of March and April 2016.

\subsubsection{Specific Objectives}

i. To determine whether individuals seeking medical attention for organophosphate poisoning are mostly incidental cases or intentional.

ii. To establish if individuals affected are aware of the different modes of poison entry into the body.

\subsection{Research Questions}

i. Are admission cases of organophosphate poisoning accidental or intentional?

ii. Are patients admitted to hospital aware of modes of organophosphate poison entry into the body?

\subsubsection{Literature Review}

\subsubsection{Introduction}

An organophosphate is the general name given for esters of phosphoric acid. Most of these are essential components of biological matter including DNA and RNA as well as some cofactors. The replacement of an oxygen atom in the organophosphorus structure by sulphur leads to the formation of organothiophosphorus compounds such as malathion and parathion, which have a lower lethal potential but in vivo metabolization to the oxon metabolite enhances their toxicity. Most organophosphates can be divided into two types: diethyl (e.g. chlorpyrifos, diazinon, parathion, phorate and dichlofenthion) and dimethyl (e.g. dimethoate, dichlorvos, fenitrothion, malathion and fenthion). In contrast to the past, when chlorinated hydrocarbon compounds such as DDT were commonly used, organophosphate insecticides have become increasingly popular for both agricultural and home use because their unstable chemical structure leads to rapid hydrolysis and little long-term accumulation in the environment.

Organophosphorus (OP) compounds have been widely used for a few decades in agriculture for crop protection and pest control. Thousands of these compounds have been screened and over one hundred of them have been marketed for these purposes [Nature and Science, 2009]. OPs constitute a heterogeneous category of chemicals specifically designed for the control of pests, weeds or plant diseases. Their application is still the most effective and accepted means for the protection of plants from pests, and has contributed significantly to enhanced agricultural productivity and crop yields [Claudia Bolognesi. Mutation Research, 2003].Some have also been used in the medical treatment of myasthenia gravis, e.g. diisopropylphosphorofluoridate (DFP), tetraethyl pyrophosphate (TEPP) and octomethylpyrophosphotetramide (OMPA). Some OP esters are still used to treat glaucoma (Ecothiopate). In addition to these beneficial agricultural, veterinary, and medical uses, some highly potent OP anticholinesterase compounds, including tabun, sarin, soman, and VX have been used as "nerve gases" in chemical warfare. They have also been used as plasticizers and stabilizers in lubricating and hydraulic oils, flame retardants, and gasoline additives [Clinical Neurology and Neurosurgery, 1992].

Examples of organophosphates include insecticides (malathion, parathion, diazinon, fenthion, dichlorvos, chlorpyrifos, ethion), nerve gases (soman, sarin, tabun, VX), ophthalmic agents (echothiophate, isoflurophate), and antihelmintics (trichlorfon). Herbicides (tribufos [DEF], merphos) are tricresyl phosphate containing industrial chemicals. 
Organophosphate compounds were first synthesized in the early 1800s when Lassaigne reacted alcohol with phosphoric acid. Shortly thereafter in 1854, Philip de Clermount described the synthesis of tetraethyl pyrophosphate at a meeting of the French Academy of Sciences. Eighty years later, Lange, in Berlin, and, Schrader, a chemist at Bayer AG, Germany, investigated the use of organophosphates as insecticides. However, the German military prevented the use of organophosphates as insecticides and instead developed an arsenal of chemical warfare agents (i.e., tabun, sarin, soman). A fourth agent, VX, was synthesized in England a decade later. During World War II, in 1941, organophosphates were reintroduced worldwide for pesticide use, as originally intended.

Massive organophosphate intoxication from suicidal and accidental events, such as the Jamaican ginger palsy incident in 1930, led to the discovery of the mechanism of action of organophosphates. In 1995, a religious sect, Aum Shinrikyo, used sarin to poison people on a Tokyo subway. Mass poisonings still occur today; in 2005, 15 victims were poisoned after accidentally ingesting ethion-contaminated food in a social ceremony in Magrawa, India.

Nerve agents have also been used in battle, notably in Iraq in the 1980s. Additionally, chemical weapons still pose a very real concern in this age of terrorist activity.

Exposure to organophosphates (OPs) is also possible via intentional or unintentional contamination of food sources. Although no clinical effects of chronic, low-level organophosphates (OPs) exposure from a food source have been shown, advancements in risk assessment and preparedness are on-going.

Organophosphates are the basis of many commonly used insecticides today. They are also part of some herbicides and nerve agents. Organophosphates are widely used as solvents, plasticizers and extreme pressure additives (lubricants).

In health, agriculture and government, the word "organophosphates" refers to a group of insecticides or nerve agents acting on the enzyme acetyl cholinesterase (the pesticide group carbamates also act on this enzyme, but through a different mechanism).

\subsubsection{Pesticide Poisoning}

The first global estimates of the extent of pesticide poisoning were published in 1990 by the World Health Organisation [WHO in collaboration with UNEP, 1990].

Based on extrapolations from limited data, it was estimated that 3 million cases of pesticide poisonings occurred world-wide annually with 220,000 deaths, the majority intentional. The WHO estimates, based on 2001 data, that 849,000 people die globally from self-harm each year [The World Health report 2002]. How many of these cases are a result of poisoning with pesticides is not known. However, poisoning is the commonest form of fatal self-harm in rural Asia, accounting for over $60 \%$ of all deaths [DJ Somasundaram, $\mathrm{S}$ Rajadurai. Acta Psychiatr Scand, 1995], and is of far greater importance than hanging, and other physical forms of self-harm. Furthermore, a review of poisoning studies reveals that pesticides are the commonest means of self-poisoning in many rural areas and associated with a high mortality rate.

A recent national survey in Bangladesh showed that $14 \%$ of all deaths $(3971$ of 28,998) of women between 10 and 50 years of age were due to self-poisoning, the majority with pesticides [Lancet, 2000]. The problem is particularly severe in Sri Lanka where pesticide poisoning was the commonest cause of hospital deaths in six rural districts during 1995[Annual Health Bulletin, 1995].

In many countries, the widespread availability of acutely toxic pesticides used in agriculture has made selection of pesticides as the agents of choice for self-harm well known to both health care workers and public health authorities.

Organophosphorus compounds have many toxicological effects on the body, some of these are:

- Respiratory disorders: The key findings were rapidly progressive bradypnoea (slow breathing) leading to apnoea (cessation of breathing) due to loss of respiratory effect and increased secretions in the airways.

- Hepatic disorders: Liver is the organ where activation and detoxification of OPcompounds take place. The histopathological changes observed in human liver observed in a forensic laboratory are: Congestion, Centrilobular necrosis, Fatty changes, Alcoholic hepatitis and Sinusoidal dilatation [Indian Acad Forensic Med, 2008].

- Cardiovascular disorders: Povoa et al [2008] have reported that OPs induced acute poisoning with myocardial necrosis.

- Neurological disorders: Neuronal necrosis has been observed in multiple cortical and subcortical regions in experimental rats exposed to large acute doses of OP compounds. OP also leads to a delay in stimulus classification, which in turn depends on attentional resources and the working memory system of the brain; this impairment appears to persist even 6 months after poisoning. Several chronic CNS disturbances due to acute or chronic OP agent poisoning have been reported in isolated cases or in worker cohorts. The syndromes vary widely and include parkinsonian and pseudo bulbar signs, alterations in effect, libido and 
memory, psychiatric or more insidious neuropsychological dysfunction and a cerebellar syndrome [Clinical Neurophysiology, 2008].

- Hormonal imbalance: In late 20th century, several experimental and epidemiological studies regarding hormonal imbalance especially sex hormones leading to adverse developmental outcomes related to pesticide exposure, including foetal death, intrauterine growth restriction, congenital malformations and male / female fertility have been published. Living in rural areas where large amounts of pesticides are applied represents a risk factor for fertility [Reproductive Toxicology, 2008].

- Renal impairment: Many studies reviewed by the Ontario College show positive associations between solid tumours and pesticide exposure, including kidney cancer. Children are constantly exposed to low levels of pesticides in their food and environment; an elevated risk of kidney cancer was associated with paternal pesticide exposure through agriculture. It has also been reported that the chronic exposure to pesticides leads to kidney failure [J Occup Med Toxicol, 2007].

- Oesophageal effects: Emergent oesophagi-gastroscopy revealed circumferential hyperthermia, oedema and bleeding throughout oesophagus [Gastrointestinal Endoscopy, 1999].

\subsubsection{Prevalence}

The first global estimates of the extent of pesticide poisoning were published in 1990 by the World Health Organisation. Based on extrapolations from limited data, it was estimated that 3 million cases of pesticide poisonings occurred world-wide annually with 220,000 deaths, majority of them intentional. The WHO estimates, based on 2001 data, show that 849,000 people die globally from self-harm each year [The World Health report 2002. Reducing risks, promoting healthy life. WHO, Geneva]. How many of these cases are a result of poisoning with pesticides is not known.

\subsubsection{Pathophysiology}

Organophosphate compounds avidly bind to cholinesterase molecules and share a similar chemical structure. In human beings, the two principal cholinesterases are RBC, or true cholinesterase (acetyl cholinesterase), and serum cholinesterase (pseudo cholinesterase).

Normally the cholinesterases rapidly hydrolyze the neurotransmitter acetylcholine into inactive fragments of choline and acetic acid after the completion of neurochemical transmission. The neurotransmitter acetylcholine is present in the terminal endings of all postganglionic parasympathetic nerves, at myo-neural junctions, and at both parasympathetic and sympathetic ganglia. The major toxicity of organophosphate compounds is the covalent binding of phosphate radicals to the active sites of the cholinesterases, transforming them into enzymatically inert proteins. Organophosphates thus act as irreversible cholinesterase inhibitors because the-organophosphate-cholinesterase bond is not spontaneously reversible without pharmacological intervention. The inhibition of cholinesterase activity leads to the accumulation of acetylcholine at synapses, causing overstimulation and subsequent disruption of transmission in both the central and peripheral nervous systems. Exposure to organophosphate compounds will, therefore, interfere with synaptic transmission peripherally at muscarinic neuro-effector junctions and nicotinic receptors within sympathetic ganglia and at skeletal myo-neural junctions. This is accomplished by an overstimulation of acetylcholine receptor sites that leads to a variety of physiologic and metabolic derangements. Disruption of transmission also will occur at the acetylcholine receptor sites within the central nervous system [Am J Med, 1971].

\subsubsection{Modes of Exposure}

OP pesticide exposure occurs through inhalation, ingestion and dermal contact. Because OP pesticides disintegrate quickly in air and light, they have been considered relatively safe to consumers. The degree of absorption depends on the contact time with the skin, the lipophilicity of the agent involved and the presence of solvents. For powders, the finer the powder the more rapid and complete is skin absorption. Other important factors include volatility of the pesticide (e.g. dichlorvos is much more volatile than Malathion), the permeability of clothing, the extent of coverage of the body surface and personal hygiene. The rate of absorption also varies with the skin region affected. For example, parathion is absorbed more readily through scrotal skin, axillae and skin of the head and neck than it is through the skin of the hands and arms. It is probable that traumatized skin or the presence of dermatitis allows greater absorption of OP compounds. In one study, the mean amount of liquid parathion absorbed dermally was only $1.23 \%$ of the measured potential dermal exposure [Absorption and excretion of Parathion by spray men. Arch Environ Health, 1972].

\subsubsection{Distribution and Storage}

Following absorption, OP compounds accumulate rapidly in fat, liver, kidneys and salivary glands. The phosphorothioates including diazonin, parathion, and bromophos, are more lipophilic than phosphates including dichlorvos, and are therefore stored extensively in fat which may account for the prolonged intoxication and 
Organophosphate Poisoning Among Patients Attending Kericho County Hospital, Kenya.

clinical relapse after apparent recovery which has been observed in poisoning from these OP insecticides. OP compounds generally are lipophilic and therefore cross the blood / brain barrier in most cases [JA Vale. Toxicology letters, 1998].

\subsubsection{Biotransformation and Elimination}

Phosphates are biologically active as acetyl cholinesterase (AChE) inhibitors, whereas phosphorothioates need bio-activation to their phosphate analogues (oxon) to become biologically active. As a consequence, the features of intoxication after exposure to phosphorothioates are delayed unless aerial oxidation has occurred already to generate traces of oxon. OP compounds other than phosphates are metabolically activated to their corresponding oxon by oxidation desulfuration mediated by $\mathrm{P} 450$ isoforms, by Flavincontaining mono-oxygenase enzymes, by N-oxidation and by S-oxidation. The oxons which inhibit AChE can be deactivated by hydrolases, such as the carboxylases and by A-esterases, for example paraoxonase [JA Vale. Toxicology letters, 1998].

Elimination of metabolites occurs mostly in urine with lesser amounts in faeces and expired air.

1.6.8 Presentation Management and Control

Signs and symptoms of acute organophosphate poisoning are according to receptor site and type.

- Muscarinic: Miosis, Blurred vision, Nausea, Vomiting, Diarrhoea, Salivation, Lacrimation, Bradycardia, Abdominal pain, Diaphoresis, Wheezing, Urinary and faecal incontinence.

- Nicotinic: Muscle fasciculations, Paralysis, Pallor, Muscle weakness, Hypertension, Tachycardia, Mydriasis (rare)

- Central Nervous System: Unconsciousness, Confusion, Toxic psychosis, Seizures, Fatigue, Respiratory depression, Dysarthria, Ataxia, Anxiety.

Laboratory Findings: Routine laboratory studies typically are unremarkable, with several notable exceptions. Non-ketotic hyperglycaemia and glycosuria have been observed in numerous case reports. Hypokalaemia also has been noted occasionally. Leucocytosis, both with and without a left shift, was a common finding in Hayes's study [M Hayes, N Van Der Westhuizen, M Gelfand. South Africa Med J, 1978]. Elevated serum amylase secondary to pancreatic injury because of parasympathetic overstimulation and hyper-secretion has been noted in human beings. The ECG may display a variety of abnormalities in acute organophosphate poisoning like, sinus bradycardia, atrioventricular block, and ST\&T wave abnormalities and prolongation of the Q-T interval also has been commonly observed.

\section{Management}

Initial phase: Resuscitation considering the airway, breathing and circulation by suctioning the airway, administration of oxygen and monitoring of blood pressure and heart rate. Then supportive management after cleaning up the patient and changing the clothing. A gastric lavage may be performed.

\section{Maintenance phase:}

Muscarinic antagonist drugs: Atropine

The aim of early therapy is to reverse cholinergic features and to improve cardiac and respiratory function as quickly as possible.

According to IPCS (1989) an initial trial dose of atropine, 1-2mg $(0.05 \mathrm{mg} / \mathrm{kg})$ intravenously,should be given slowly over $3 \mathrm{~min}$, and then repeated every 5-10 $\mathrm{min}$ if there is no observableadverse effect. In symptomatic children, intravenous dose of $0.015-0.05 \mathrm{mg} / \mathrm{kg}$ atropineshould be administered every $15 \mathrm{~min}$ as needed. Atropine may then be repeated or increased in increments at 15-30 min intervals until bronchial secretions are cleared and the patient is atropinized (dilated pupils, dry skin, and skin flushing) which should be maintained during further treatment. Repeated evaluations of the quantity of the secretions through regular auscultation of the lungs are the only adequate measure of atropinization in the severely poisoned patient. The dose may be increased as required.

Oximes: Oximes reactivate acetyl cholinesterase inhibition by Organophosphorus. Among the many classes of oximes investigated so far, those with clinical application can be divided in two groups - the monopyridinium and bispyridinium oximes. Currently, the only usedmonopyridinium oxime is pralidoxime (PAM-2), while the most significant bispyridiniumoximes comprise: trimedoxime (TMB-4), obidoxime (LuH-6, Toxogonin) and asoxime (HI-6),

\subsection{Study Area}

\section{Methodology}

This study was conducted at Kericho County Hospital, Kericho County. 
Organophosphate Poisoning Among Patients Attending Kericho County Hospital, Kenya.

Kericho County is one of the 47 counties in Kenya with a population of 752,396 as per the 2009 census. It covers an area of $2,111 \mathrm{Km}^{2}$. Its capital and largest town is Kericho. The County is known for being the home of the best of Kenyan tea which is renowned worldwide for its taste with its town square even known as Chai Square.

Other sub-counties other than Kericho town include Kipkelion and Londiani. Administrative divisions include Ainamoi, Kericho, Belgut, Kabianga, Chilchila, Londiani, Sigowet and Soin. Electoral constituencies include Ainamoi, Belgut, Bureti, Kipkelion East and West and Sigowet-Soin Constituencies.

Percentage urbanisation is $28.3 \%$, a literacy level of $79 \%$ with those attending school being $79.7 \%$ (Between ages $15-18$ ), $13.8 \%$ paved roads, $58.5 \%$ being good roads, an electricity access of $11.8 \%$ and a poverty rate of $44.2 \%$.

\subsection{Study Design}

Descriptive cross sectional study design was used.

\subsection{Study Population}

The study population were patients attending Kericho County Hospital and suffering from organophosphate poisoning.

\subsection{Sampling Technique}

A convenience sampling technique was used to obtain respondents who would provide the information required. The respondents for the study were purposely picked.

\subsection{Data Collection Technique}

Data was collected using an interview schedule and records.

\subsection{Quality Control}

\subsubsection{Inclusion Criteria}

The study included individuals 15-40 years old attending Kericho County Hospital, who had suffered organophosphate poisoning and were willing to take part in the study.

\subsubsection{Exclusion Criteria}

The study excluded all individuals seeking medical attention below the age of 15 or above the age of 40 regardless of their exposure status and those who were unwilling to take part in the study even if suffering from organophosphate poisoning.

\subsection{Ethical Consideration}

This research was conducted only after the approval by the Ethics Research Committee of Egerton University and also with permission granted by medical superintendent, Kericho County Hospital. Informed consent was sought from the participants in this study. All the information from the clients was treated as private and confidential.

\subsection{Data Processing and Analysis}

All data collected was classified according to the objectives of the study and variables and analyzed using Microsoft excel and SPSS version 23.

\section{Study Findings}

3.1 Prevalence of Organophosphate poisoning

Of the patients reviewed 35 out of 716 individuals (5\%) who attended Kericho County Hospital suffered from organophosphate poisoning. This is the third most prevalent condition after road traffic accidents and other medical and surgical conditions.

Table 1: Prevalence of Different Conditions Encountered at Kericho County Referral Hospital

\begin{tabular}{|l|l|}
\hline Condition & Number \\
\hline Organophosphate Poisoning & 35 \\
\hline Road traffic accidents & 150 \\
\hline Other medical and surgical conditions & 531 \\
\hline Total & 716 \\
\hline
\end{tabular}


A graphical representation of the different conditions is shown below:

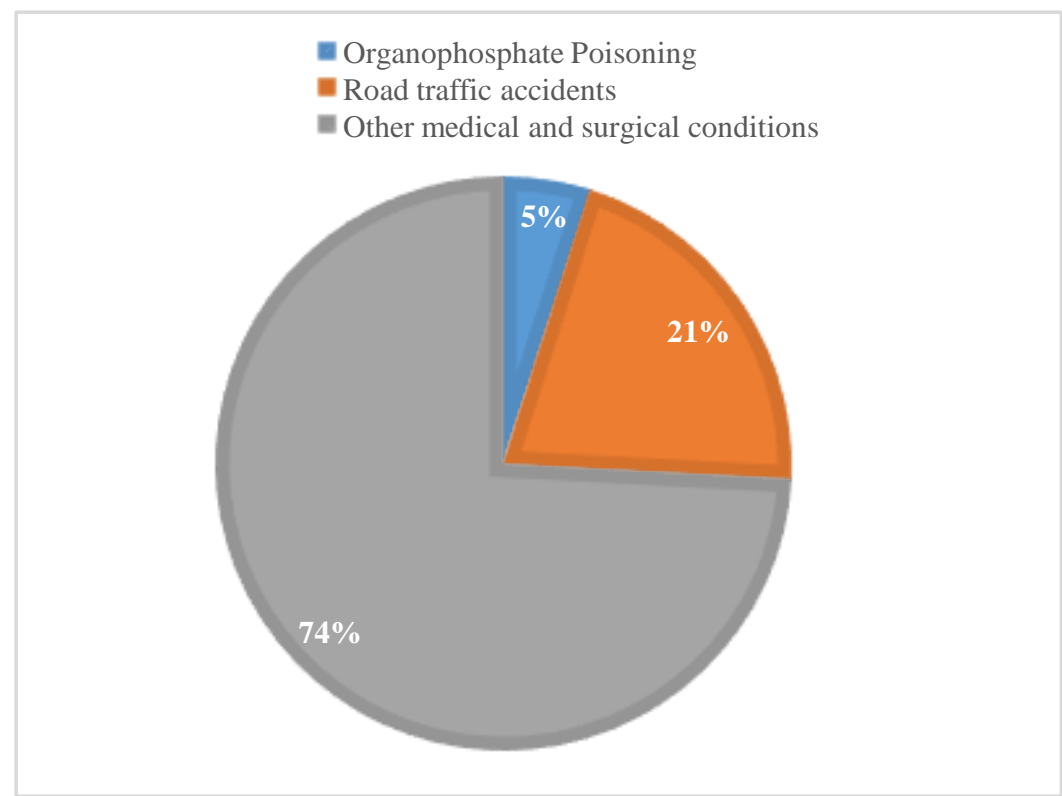

Figure 1: Prevalence of Different Conditions Encountered at Kericho County Referral Hospital

\subsection{Gender Distribution}

There was a male predominance with 29 males out of the 35 individuals having had organophosphate poisoning. Below (Figure 2) is a graphical representation.

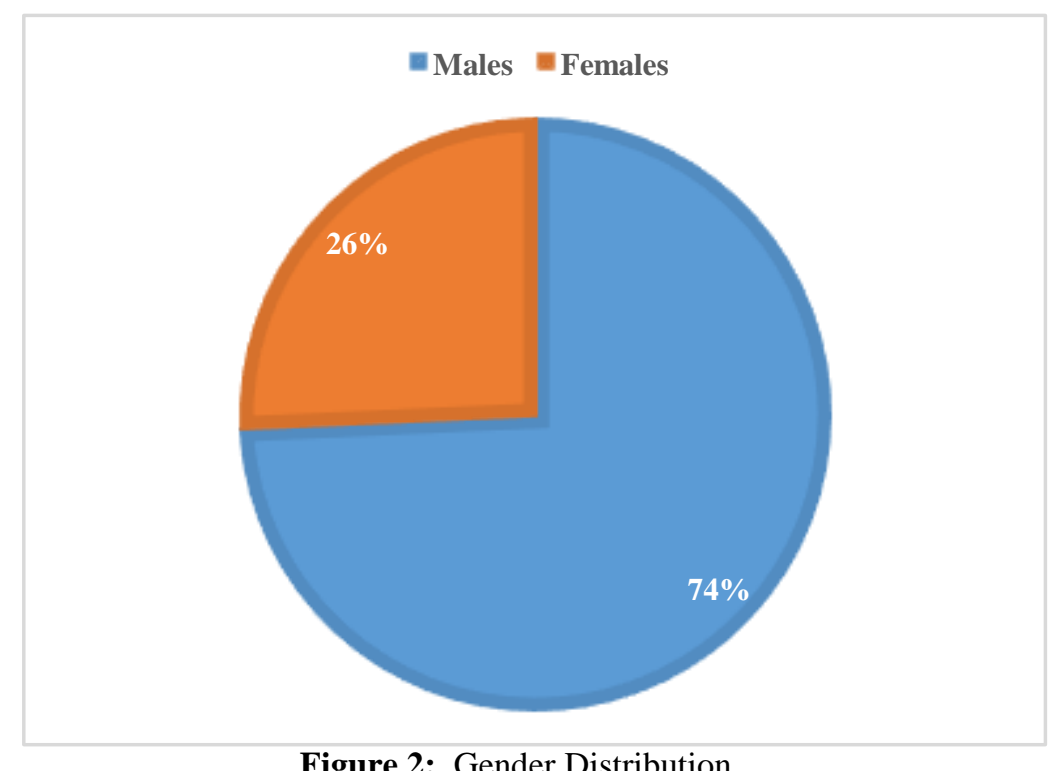

Figure 2: Gender Distribution

Frequency Distribution according to Age andTime of Admission

Table 2 : Frequency Distribution as per Age and Time of Admission

\begin{tabular}{|l|l|l|l|l|}
\hline & & & \multicolumn{2}{l|}{ Time of Admission } \\
\hline Age & Number & Percentage & Day & Night \\
\hline $15-20$ & 10 & 29 & 3 & 7 \\
\hline $21-25$ & 6 & 17 & 1 & 5 \\
\hline $26-30$ & 6 & 17 & 3 & 3 \\
\hline $31-35$ & 8 & 23 & 5 & 3 \\
\hline $36-40$ & 3 & 9 & 1 & 2 \\
\hline Undefined & 2 & 6 & None & 2 \\
\hline Total & 35 & 100 & 13 & 22 \\
\hline
\end{tabular}


A majority of the individuals admitted at the hospital were between the ages of 15 and 20 followed by the ages between 31 and 35. This is due to the fact that a majority of individuals, 33 out of 35, are due to issues related to being in a relationship. A bar graph representation (Figure 3) and a pie chart (Figure 4) are shown below:

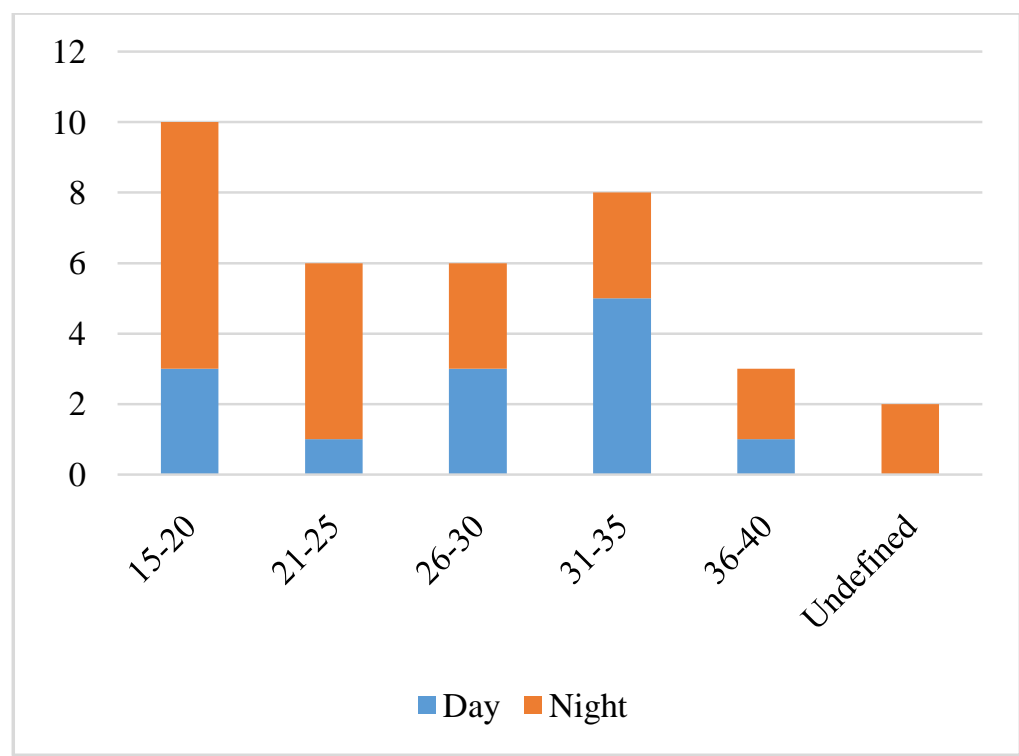

Figure 3Frequency Distribution According to Age and Time of AdmissionThe younger group is that of those who are first timers in relationships while the older group is that of those who were recently married. Only two had reasons not related to relationship. They felt that they were not achieving as per what was expected in school and at work. A graphical representation of this (Figure 4) is shown below:

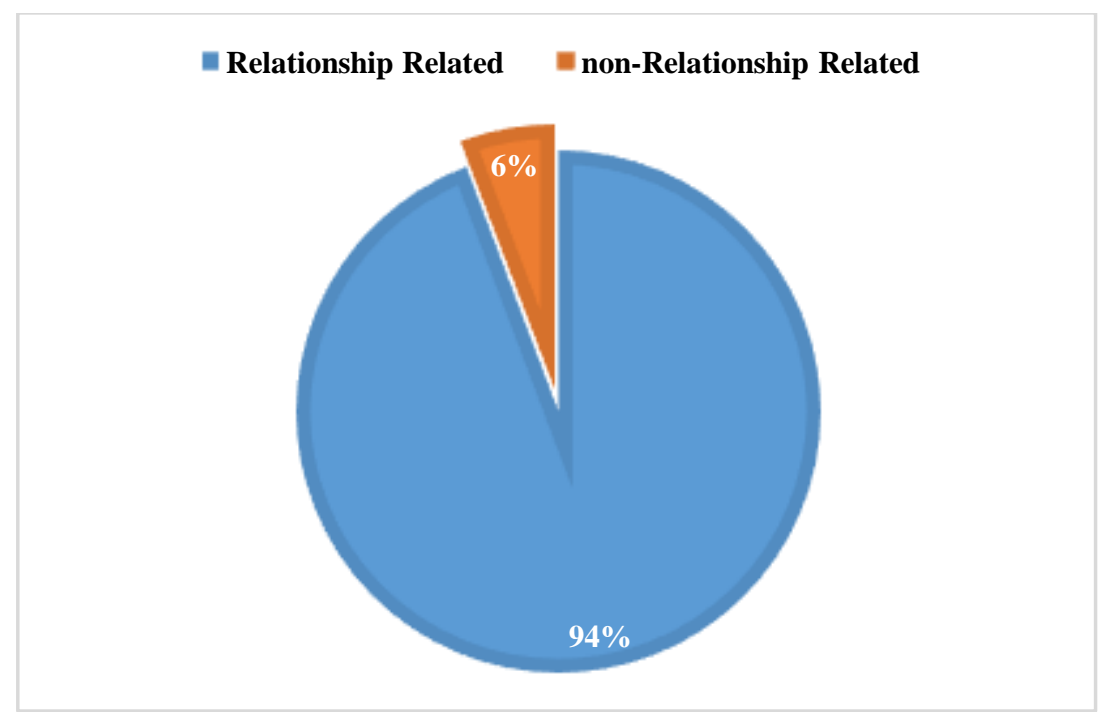

Figure 4 : Reason for Poisoning

A majority aimed at dying from consuming the poison while a minority was seeking attention. It is important to note that the timing at which an individual was admitted reflected the intention and severity. 16 individuals who were admitted into the medical wards, a majority, came at night. The other 19 were not admitted but managed acutely at the outpatient department and discharged. 
In addition, majority of those who attended hospital were of the lower socio-economic status and a large number of those who suffered organophosphate poisoning were casual labourers while for the young, these were those who had dropped out of school and were trying to make a living from casual labour.

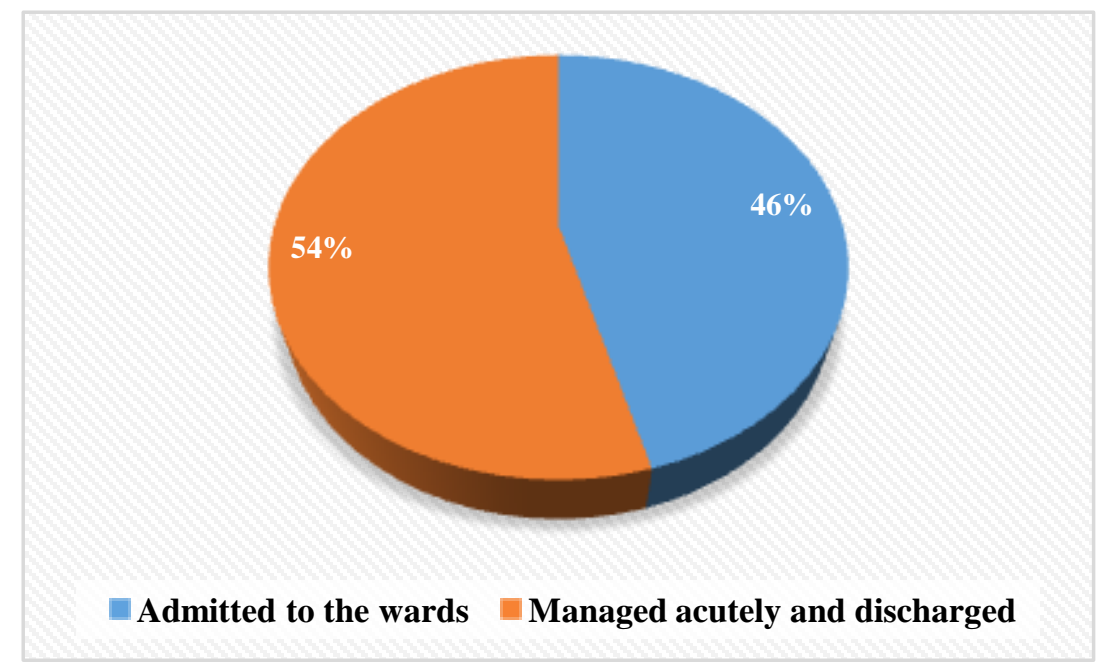

Figure 5: Hospital stay

\subsection{Symptomatology and Outcome}

Of 11 individuals admitted to the medical wards 9 were semi-conscious while 2 were unconscious. Other symptoms as per the individuals are as follows (Table 3):

Table 3: Symptomatology of those admitted

\begin{tabular}{|l|l|}
\hline Symptom & Number \\
\hline Nausea and vomiting & 9 \\
\hline Abdominal pain & 9 \\
\hline Urinary incontinence & 3 \\
\hline Difficulty in Breathing & 5 \\
\hline Fast heart rate & 7 \\
\hline Confusion or Anxiety & 7 \\
\hline Sweating & 9 \\
\hline Abnormal Muscle Movement & 1 \\
\hline Fatigue & 7 \\
\hline Blurred vision & 1 \\
\hline Tearing & 2 \\
\hline Salivation & 2 \\
\hline
\end{tabular}

As per the above data, the most common symptoms include nausea and vomiting, abdominal pain, palpitations, confusion and anxiety, sweating and fatigue.

During the month only one case had a recurrence of the condition who had to be referred to a psychiatrist for further management.

Of all 35 cases who suffered organophosphate poisoning one died from the poisoning. He was unconscious when he was admitted, with respiratory depression. He was treated with large amounts of antidotes, but died. For those who were interviewed no individual suffered long term complications after appropriate management following admission.

\subsection{Discussion}

\section{Discussion, Conclusions And Recommendations}

\section{Summary}

Organophosphates are widely used in the household and in agriculture largely as insecticides due to their effectiveness and reduced human toxicity at doses that are used in killing harmful insects. Intoxication with organophosphates is a worldwide problem and may cause severe morbidity and mortality majorly due to their wide availability.

Prevalence of Organophosphate PoisoningOf the records reviewed 35 out of 716 individuals attending Kericho Referral Hospital suffered organophosphate poisoning. This is the third most prevalent condition after road traffic accidents with the specific medical and surgical conditions accounting for a larger number than organophosphate poisoning. This represents $5 \%$ of all the individuals attending Kericho County Referral 
Organophosphate Poisoning Among Patients Attending Kericho County Hospital, Kenya.

Hospital. This is the case mainly due to socio-economic reasons that prevail in this region as many of the individuals are middle and low income citizens.

\section{Gender Distribution}

The number of males affected was larger than that of the females. There were 29 males and 6 females. This represented a male predominance at a percentage of $74 \%$ and a female percentage of $26 \%$. This is attributable to the social factors that define the communities living around this area. Culturally in this community, males are not 'allowed' to crumble due to 'small' issues affecting them. This means that they do not have a way of stress relief which leads them to depression and subsequently tendency to commit suicide and in this region mainly via organophosphate poisoning. The females were more open and they discussed their issues with other people. This is a way of stress management and it therefore means that the stress levels were lower among the females. Males are supposed to be the providers in the family and are basically supposed to be the head of the family. Failure tobe calm and strong without displaying emotion is thus not tolerated in this community. It is thus reflected in the pattern in which a larger number of those with poisoning are of the male gender.

\section{Frequency of Distribution According to Age, Reason and Time of Admission}

There was a variation in the age distribution. Majority of the individuals were between the age of 15 and 20 representing $29 \%$ of the total. The next group is that of the ages between 31 and 35 with a percentage of $23 \%$. The next at $17 \%$ are the ages between 21 and 25 and the ages 26 and 30 . The next group is that of ages 36 and 40 at $9 \%$ and $6 \%$ of those whose age was not defined.

From the above there are two predominant groups that of 15 to 20 and that of 31 to 35 . It is worth noting that the main reason why individuals suffered organophosphate poisoning was relationship wrangles. The younger group is that of those who are first time in relationships and the second group is majorly of those who were not long into their marriage.

Of the total 35only two had other reasons other than relationship issues representing $6 \%$ of those who suffered organophosphate poisoning. The reasons for the two were education and financial constraint from low returns from work.

The bigger number of individuals came at night $63 \%$ against $37 \%$ who came during the day. A majority of those that came at night wanted to die representing $78 \%$ against $49 \%$ who came during the day. The others took the poison for the purpose of seeking attention. $46 \%$ of the patients were admitted into the medical wards for further management with the others having being treated at the outpatient department and discharged. Most of these were admitted at night and it was a marker of severity. There is thus a relationship between the time of admission, time of management and severity.

\section{Symptomatology and Outcome}

Many of the patients were admitted in a semi-conscious and unconscious state. This can also be viewed as a marker of severity. Gastrointestinal symptoms were the most common in virtually all the patients admitted; that is abdominal pain, nausea and vomiting and diarrhea. Sweating was a common feature. Palpitations, confusion and anxiety, fatigue and difficulty in breathing were the next most common features. Urinary incontinence, blurred vision, tearing and salivation appeared to be the least reported symptoms. The gastrointestinal symptoms may have been the most common as they are usually the most dramatic and they might have masked the other symptoms as there is currently no scientific basis to explain that fact.

During the month one case had a recurrence of the condition. This was a 35-year-old male who had to be referred to a psychiatrist for further management. This may be attributable to the fact that there was no counselling system in the hospital during the time of study.Of all 35 cases who suffered organophosphate poisoning one patient died from the poisoning. He was unconscious when he was admitted, with respiratory depression and was managed efficiently basically as per the WHO guidelines on OPP, but died. For those who were interviewed later no individual suffered long term complications following competent management after admission. This may be due to the vigilance and the proficiency of the clinicians involved may be due to the experience achieved from the large number of patients who came to the hospital due to organophosphate poisoning.

\subsection{Conclusion}

a. 5\% of patients admitted in a hospital is quite high considering it is only organophosphate poisoning let alone other kinds of poisons.

b. A higher percentage i.e. $74 \%$ is of the male gender attributable to the socio-cultural and economic situation surrounding them and were mainly attributed to relationship wrangles both in those who were married and those who were not.

c. Majority of the patients who suffered organophosphate poisoning aimed at dying and this influenced the severity of the poisoning at patient presentation during admission and duration of stay in hospital. 
d. Gastrointestinal symptoms were the most common presenting symptoms in that they are the most dramatic and most noticeable.

e. Proper ways of management of these patients has meant that the death rate is low and this meant a good prognosis.

\subsection{Recommendations}

The study recommends that there be a multi-sectoral approach in trying to combat this problem. The government has the larger role to play followed by the community and finally health service providers and other professionals in both the medical field or outside like counsellors.

The role of the government is to:

1. Work towards raising the standards of living of the community living around Kericho County Referral Hospital. With raised standards of living there is less stress among individuals and less likelihood of suicide. This means job creation, improvement of infrastructure, social services and housing. This will reduce relationship wrangles and further reduce stresses from financial burden that causes suicidal tendencies.

2. Facilitate opening up of a counselling unit in the hospital for the cases that have had organophosphate poisoning so as to reduce a likelihood of organophosphate poisoning recurrence over the long term.

The community's role involves:

1. Establishing community based counselling programmes that offer counselling to individuals who are having trouble in society especially in relationships.

\section{The health service providers should be involved in:}

1. Taking part in the counselling ofpatientsrather than just treating the patients and discharging them after that.

\section{References}

[1]. KM Mogda, Afaf AI El-Kashoury, MA Rashed, KM, Nature and Science, 2009

[2]. Claudia Bolognesi. Mutation Research, 2003

[3]. Jan L De Bleeker, Jacques L De Reuck, Jan L Willems. Clinical Neurology and Neurosurgery, 1992

[4]. https://en.wikipedia.org/wiki/Organophosphate

[5]. https://en.wikipedia.org/wiki/Organophosphate_poisoning

[6]. Stedman's Electronic Medical Dictionary, $7^{\text {th }}$ edition by Stedman

[7]. J Veltri, T Litovitz: 1983 Annual report of the American association of poison control centers national data collection system. Am J Emerg Med, 1984

[8]. WHO in collaboration with UNEP, 1990. Public Health Impact of Pesticides used in Agriculture. Updated June 2007, WHO, Geneva.

[9]. WHO, 2002. The World Health report 2002. Reducing risks, promoting healthy life. WHO, Geneva.

[10]. MR Phillips, Y Li X Zhang. 1995-99. Lancet, 2002

[11]. LR Berger. Am J Public Health, 1988,

[12]. T Dassanayake, V Weerasinghe, U Dangahadeniya, K Kularatne, A Dawson, L Karalliedde, et al. Clinical Neurophysiology, 2008

[13]. C Maurizio, MT Gian, C Roberto, LR Cinzia, M Francesca, R Francesco, et al.Reproductive Toxicology, 2008

[14]. K Hideki, Y Mayumi, A Kunihiko, Y Hiroshi, L Mitsuo, F Masatoshi. Gastrointestinal Endoscopy, 1999, 